\title{
To study the requirements of quality standards of NABH/ NABL
}

\author{
Shashikala G. Hiremani ${ }^{*}$, Dasharath. S. Hosamani ${ }^{2}$, Renuka M. Patil ${ }^{3}$, Mahesh B. More ${ }^{4}$, Shivananda, M. \\ Gundalli $^{5}$, Ravindra G. Patil ${ }^{6}$ \\ ${ }_{1,5,6}$ Pathologist, ${ }^{2,3}$ Paediatrician, ${ }^{4}$ Microbiologist, ${ }^{1,5,6}$ Dept. of Pathology, ${ }^{2,3}$ Dept. of Paediatric, ${ }^{4}$ Dept. of Microbiology, \\ 1,2,3,4,5 District Hospital Vijayapur, Health and Family Welfare, Karnataka, ${ }^{6}$ District Hospital Bagalkot, Health and Family \\ Welfare Karnataka, India \\ *Corresponding Author: Shashikala G Hiremani \\ Email: drshashikalagh@gmail.com
}

\begin{abstract}
Introduction:. Hospitals are integral component of health care and hospital staff to do their best for good quality services and patients satisfactions. Quality standards of National Accreditation Board for the Hospital and Health care providers (NABH) / National Accreditation Board for testing and calibration Laboratories (NABL) are today highest benchmark standards for hospital quality in India

Aim and Objectives: To study the requirements of quality standards of NABH/NABL and try to implement the same in District hospital.

Materials and Methods: For this project study requirements of quality standards of NABH/ NABL in District hospital Vijayapur selected. To make project literatures were referred for review of hospital and facilities. This Project was done with pre assessment study and then intervention of implementation of quality standards done by sensitizing staff about the quality standards of NABH/NABL in this hospital and implemented of quality standards across the hospital and also with the help of questionnaires by taking patients interview about their satisfaction towards quality of health services

Results: Majority quality standards are implemented and made them complianced. And remaining non complianced quality standards reviews are noted.

Conclusion: Implemented many quality standards, successfully made noncompliance standards to compliance and recommendations are suggested for noncompliance standards to make compliance in future and non available services and staffs. Most of the patients were satisfied with the quality of hospital services.
\end{abstract}

Keywords: Hospital, NABH, Standards, Accreditation, Quality.

\section{Introduction}

Accreditation is procedure by which an authorisation body gives formal recognisation that an organization is competent to carry out specific tasks.

The NABH Standards is today the highest benchmark standards for hospital quality in India. $\mathrm{NABH}$ standards are equally applicable to Government and private hospitals and are applicable to whole organisation. ${ }^{1}$

NABH is a constituent board of Quality council of India, set to establish with objectives of enhancing health system promoting continuous quality improvement and patient safety. ${ }^{2}$ Just within two years of its launch, the Indian Accreditation Standards, the NABH was accepted by the International Society for the Quality assurance in health care (ISQua), as an International Accreditation on par with the world's best. Though developed by the quality council of India on the lines of International Accreditation Standards like the Joint commission on Accreditation of Hospital (JCA) ${ }^{3}$ and the Canadian Hospital Accreditation Standards (CHAS), the NABH is however seen as a more practical set of standards, topical and very relevant to India's unique health care system requirements. The Government and private corporate hospitals by the virtue of their objectives typically have inbuilt quality culture and these have been undergoing certification for various accreditation standards. ${ }^{4}$ But these NABH standards shall facilitate health care organisation to deliver safe high quality care and these standards are dynamic and would be under constant review process. ${ }^{1}$ Not only does require up gradation of quality system to handle higher patient load, but emphasis also needs to be given to availability aspects to increase level of patient satisfaction. ${ }^{4}$

In India health system currently operates within an environment of rapid social, economical and technical changes. Such changes raise the concern for quality of health care. ${ }^{2}$

\section{Benefits of Accreditation Benefits of Patients}

Patients are the biggest beneficiary among all the stake holders. Accreditation results in quality of care and patient safety and patients are serviced by credential 
medical staff. Rights of patient's are respected and protected. Patient's satisfaction is regularly evaluated.

\section{Benefits of Staff}

It provides for continuous learning, good working environment, leadership and above all ownership of clinical processes. It improves overall professional and skills development of the staff.

\section{Benefits of Hospital}

Finally, Accreditation provides and objective system of empanelment by insurance and other third parties. Accreditation provides access to reliable and certified information on facilities, infrastructure and level of care National Accreditation Board for testing and calibration Laboratories (NABL), similar to the $\mathrm{NABH}$, is also an autonomous body, under the quality Council of India. The primary objective of NABL being to maintain an Accreditation system for laboratories suitable for India and developed in accordance with relevant National and International Standards and guidelines.

\section{Aim of study}

To study the requirements of quality standards of $\mathrm{NABH} / \mathrm{NABL}$, try to implement those quality standards and to evaluate compliance of implemented standards in terms of quality of health services.

\section{Objectives}

To study the requirement of quality standards of NABH/NABL in District Hospital Vijayapur.

\section{General objectives}

General objectives of this project/study were to study the requirement of quality standards of NABH/NABL in District Hospital Vijayapur.

\section{Specific objectives}

1. To study the present quality assurance system with the requirement of quality standards as per $\mathrm{NABH} / \mathrm{NABL}$ for good patient care in District Hospital Vijayapur.

2. To suggest change in the quality practices for improvement of patient care.

\section{Materials and Methods \\ Study design}

This project study descriptive analytical study. Before proceeding to project study, we should know about NABH Cell Organisation structure as Fig.1. We should study the NABH Accreditation procedure as in
Fig. 2. We should follow the steps for preparing for NABH Accreditation ${ }^{3}$. We should know all NABH quality standards as per each chapter as in Fig. 4. Then we should prepare schematic representation of project design as in Fig.5. We should do the pre-project Situational Survey analysis and analyse the quality standards situation in the facility. So pre-project Situational Survey analysis carried out by Internal Assessment Committee and Gap analysis done among 102 standards, few were implemented, others to be require implementation during project period. For the implementation of noncomplianced quality standards, action plan is required. According to implementation requirement action plan is prepared. In the action plan sensitisation about all NABH quality standards to staff is planned and trainings are conducted. Many committees are formed which supervised the implementation of quality standards across the different functional areas of hospital. And this project also consists of pilot questionnaire. These pilot questionnaires prepared, these questionnaires were arranged for 20 - 40 indoor patients and 10-20 outdoor patient's interviews were taken. Questions were typed in a prescribed format about patients services, where he met about billing, receipt, department services, water facility services etc. And if patient educated, he should attempt the patient satisfaction report and tick the answer, if he is uneducated, he can give his opinion with the help of staff nurse or attenders. Patients will wright their experience about services and give their valuable suggestion regarding improvement of quality services of hospital.

At the end of the project study, the internal assessment committee do the internal assessment of successful implementation, successful closing gaps are assessed and remaining gaps are identified and action plans are prepared to fill the gaps. Patient satisfaction report format also collected, analysed, suggestions are discussed, for implementation of patient suggestions action plan is prepared. From the whole analysis, conclusion is made and necessary recommendation and suggestion were prepared. 


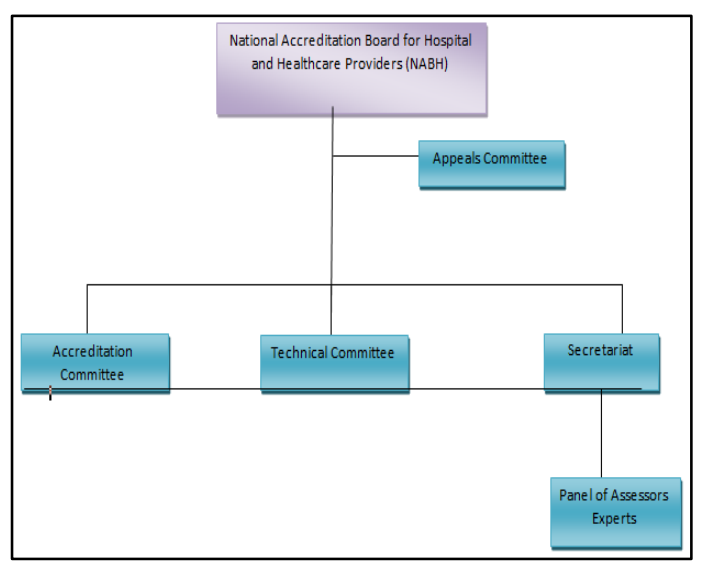

Fig. 1: Organisation structure of NABH

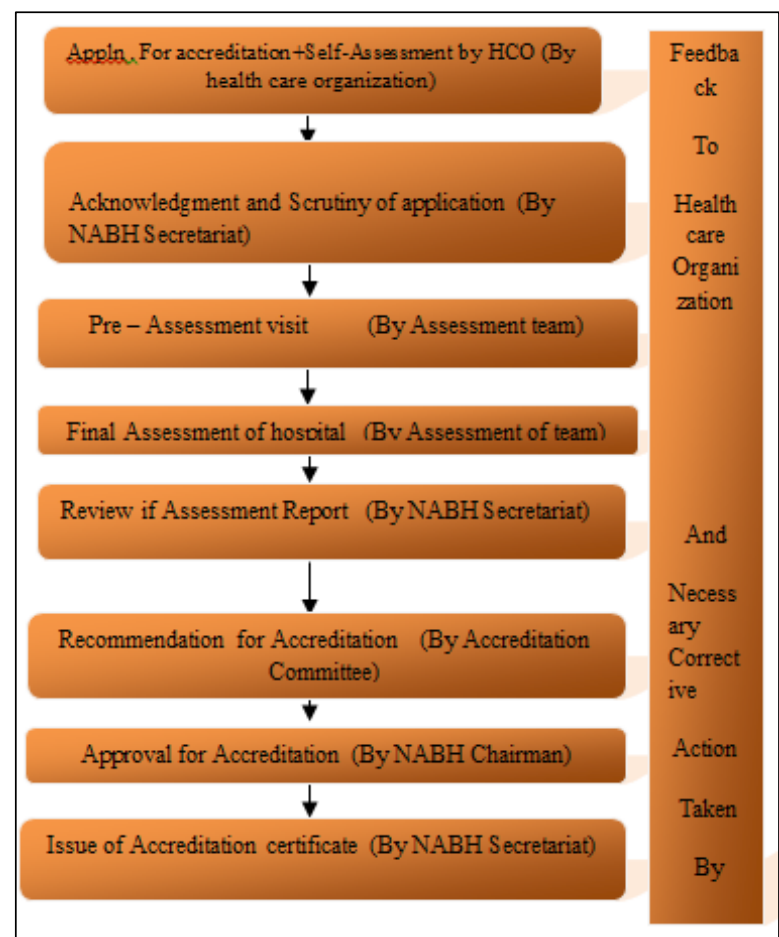

Fig. 2: NABH Accreditation Procedure

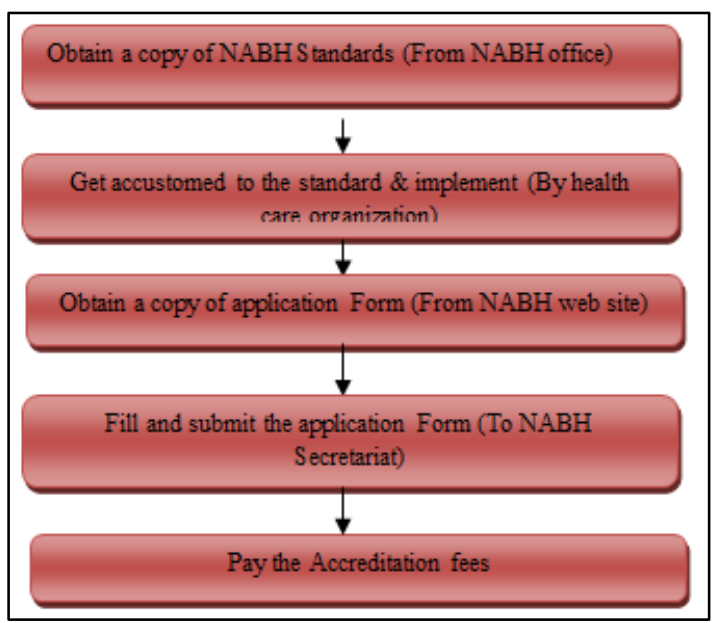

Fig. 3: Steps for Preparing for NABH Accreditation

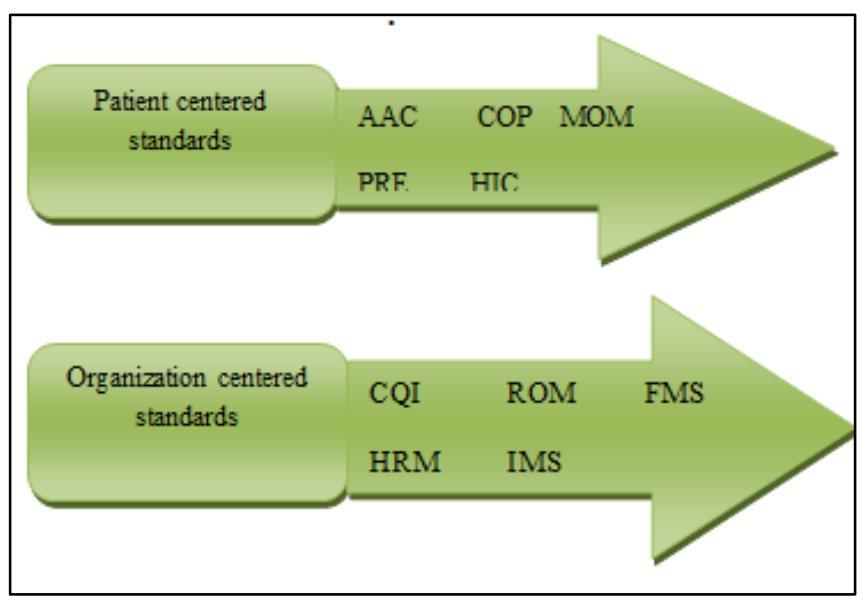

Fig. 4: NABH Quality Standards

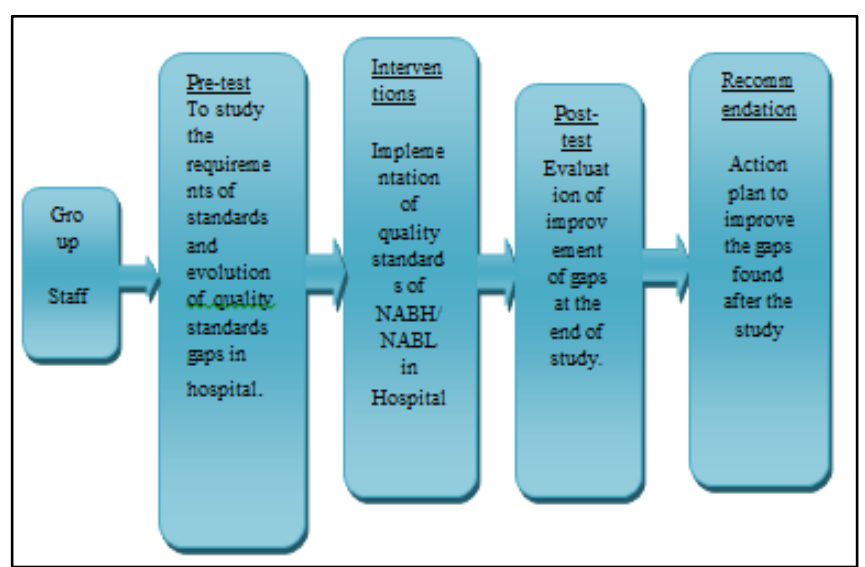

Fig. 5: Schematic representation of project design

\section{NABH Quality Standards}

The NABH quality standards provides frame work for the quality of patient care and quality improvement for all levels of health organisation and these standards help to build a quality culture at Hospitals also.

The NABH/ NABL quality standards for hospitals prepared by technical committee, which have plans to evaluation of complete set of standards, for grant of accreditation at hospitals. NABH/ NABL quality Standards have 10 chapters as in Fig. 4, incorporating 102 Standards and 636 objective elements. ${ }^{1}$

\section{Outline of NABH Standards chapter wise: Patient centered Standards:}

1. Access, Assessment and Continuity of care (AAC).

2. Care of Patients (COP).

3. Management of Medication (MOM).

4. Patient's Rights and Education (PRE).

5. Hospital Infection Control (HIC).

Organisation Centered Standards:

1. Continuous Quality Improvement (CQI). 
2. Responsibilities of Management (ROM).

3. Facility Management and Safety (FMS).

4. Human Resource Management (HRM).

5. Information Management System (IMS).

\section{Study Area}

District Hospital Vijayapur, Karnataka state, situated in 115 Acres, building area is about 60 acres and having 350 beds. Hospital covers five Talukas, greater than 100 villages and 14 laks of population. All community people visit to this hospital for the Hospital services. Because as this hospital has highly skilled staff and multispecialty doctors and around clock causality medical officer team will serve for $24 * 7$ for the society. Their main aim is to stay with patients and cure their diseases and problems regarding health and use their education and knowledge skills for such a noble cause.

This hospital has good team of 31 doctors including Physicians (03),Surgeons(04), Ortho surgeons (02), Paediatricians (03), Gynaecologist (04),Psychiatrist (01), Pathologist (01), Microbiologist (02), Bloodbank officer (01), Nephrologist(01), Dermatologist(01), SNCU medical officers (02), Ophlomologist (01), ENT surgeon (01), Dentist (02), Physiotherapist (01), District surgeon (01), Group B (18), Group C (73), Group D (64). Total staff 186. Hospital faculties include Medicine, surgery, Gynaecology, Psychiatry, Dermatology, Radiology, Pathology, Biochemistry, Microbiology department with high-tech laboratories, Physiotherapy unit, visiting departments are Cardiac, Oncology and WHO health consultants to SNCU.

\section{Study Population}

District Hospital Vijayapur covers five Talukas, greater than 100 villages encompassing of 14 laks of population.

\section{Population Profile}

1. Population is belongs to below poverty line (BPL) holders $60-80 \%$.

2. Majority are literate people.

3. Malnutrition on children (PEM) are highly among up to $60 \%$ paediatric age, only $1 / 3$ of children are with normal growth.

4. Severe Anaemia is antenatal case more than $2 / 3$ of total maternity cases.

5. Average Haemoglobin is about $8-10$ gms.

6. Majority patients are Maternity, ART patients, Paediatric, Chronic Anaemia and Thalassemia patients who need blood transfusion on and off.
7. Around $40 \%$ of hospital patients are coming from poor rural villages where facilities for transportation are poor.

\section{Sample size}

For the implementation of quality standards across the facility, all hospital staff were selected and for "Patient satisfaction report form" questionnaire interviews arranged for 20 - 40 indoor patients randomly from different wards and 10-20outdoor patients randomly from drug counter, reception areas, cash counters, OPDs, laboratories, X-ray, USG, Physiotherapy units.

\section{Criteria for sample study Inclusion criteria}

1. Patients selected from district hospital Vijayapur.

2. Patients who are cooperative and willing to participate in study.

\section{Exclusion criteria}

1. Patients who are not available during data collection.

2. Patients who are not willing to participate.

\section{Study period}

This project is studied for 45 days, started from $15 / 2 / 2016$ to $31 / 2 / 2016$.

\section{Research tools}

Proceeding with study

1. Prepare requirements of hospital for accreditation procedure.

2. Situational survey by Internal Assessment committee carried out to create a baseline documents as a Situational survey report, this survey does the analysis and evaluation of quality standards and identify the gaps of Quality Standards.

3. Results of Situational survey report.

4. Development of Action plan to bridge gaps of quality standards.

5. Implementation process.

6. Monitoring.

\section{Assessment criteria}

A Hospital willing to be accredited by NABH must ensure the implementation of NABH/NABL Standards in its organisation. The Internal Assessment committee will do the assessment of the implementation of $\mathrm{NABH} / \mathrm{NABL}$ Standards in organisation, Intra Department, Inter Department wise and submit its assessment report as Internal Assessment report to Core assessment committee. Core assessment 
committee will review this Internal Assessment report, assess and plans accordingly as in Fig.6. The Hospital shall be able to demonstrate to NABH Assessment team that all NABH Standards as applicable and are followed strictly.

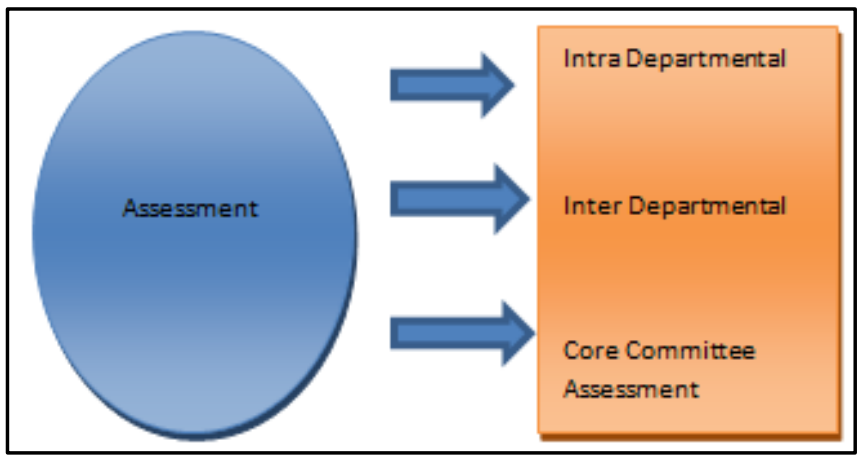

Fig. 6: Assessment

\section{Process}

Prepare requirements of hospital accreditation procedure: The requirements of the NABH standards shall have to be identified, evidenced by data gathered, analysed and interpreted with the aim of improving the quality system of a hospital.

\section{a. Apply for accreditation by filling application} form

To take participation in $\mathrm{NABH} / \mathrm{NABL}$ accreditation, organisation can obtain application form from NABH/NABL Secretariats office or download from website of NABH/NABL as shown in Fig.2 and proceeded as Fig. 3. Our hospital downloaded from website filled and signed by District surgeon and submitted to same office with help of KHSDRP and Astron consultation 9(pvt) in December 2014, then activity started slowly, staffs are trained at Bangalore, gained movement after few visits of $\mathrm{NABH}$ consultant, slowly progressed to situational state.

b. Obtain copy of NABH/NABL quality standards-

Obtain copy of NABH/NABL quality standards from NABH/NABL office as shown in Fig. 3. So obtained copy of same and it consist of 10 chapters as Fig. 4, 102 quality standards and 636 objective elements.

\section{Situational Survey to carried out to create a} baseline document-

Situational survey to carried out to study the baseline situation of the facility with available documents. Situational survey to carried out from 16/2/2016 to 20/02/2016. To carry out Situational Survey, Internal assessment committee formed. This committee consist of all various committee heads. According to quality standards guidelines of NABH/NABL this committee conducted the Situational survey. This team studied and evaluated each quality standards according to chapter wise serially and following Situational survey report submitted to Core assessment committee.

\section{Results of Situational Survey report}

All 102quality standards are studied thoroughly, following results are obtained as in Fig. 7.

Total quality standards are 102.

Total complianced quality standards are 52.

Total non complianced quality standards are 50.

Gap areas are identified in various departments. Reception counter, OPDs, Wards, Laboratory and Operation Theatre.

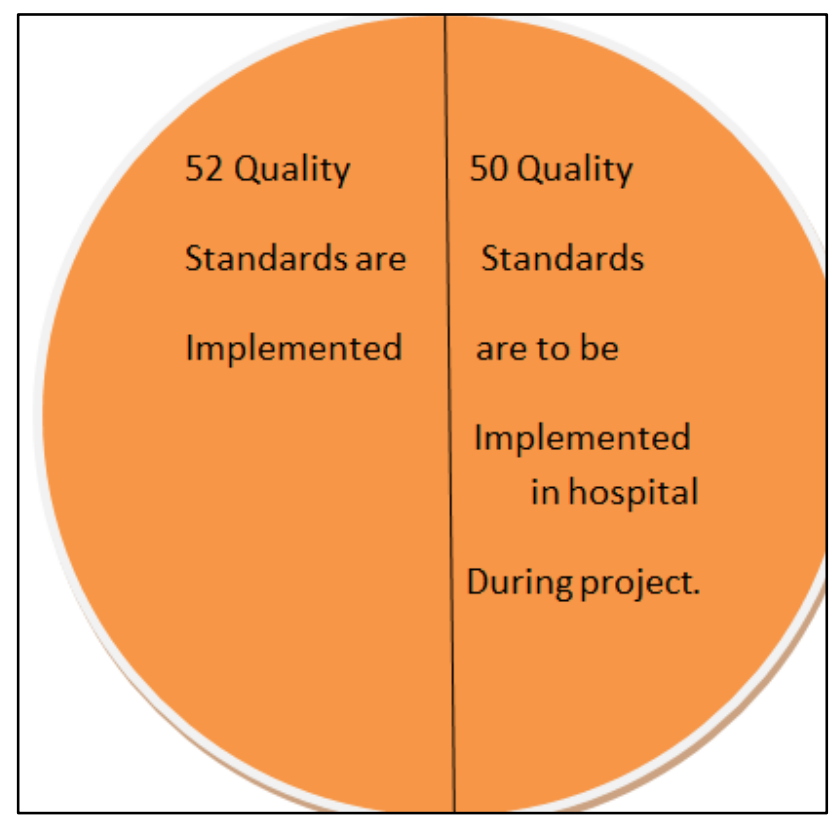

Fig. 7: Among 102 quality standards, 52 are implemented and 50 are to be implemented during project period as per Situational survey.

\section{Action Plan}

Action plan needs to bridge the gaps.

The action plan to implement the quality standards in our hospital prepared as Systematic approach. This Systematic approach consists of following steps.

1. Initiation

2. Documentation

3. Structural requirements

4. Statutory requirements 


\section{Initiation}

\section{Involves following steps}

A. Constitutional of Teams.

B. Sensitisation.

C. Understandingstandards.

\section{A. Constitutional of Teams *Chapter Champions}

For constitution of team, meeting conducted by District surgeon and NABH coordinator on $15 / 02 / 2016$ at DS chamber, under their guidance, HODs were made as Star champions, allotted each chapter and assign their responsibility to implement their chapter quality standards across the facility. Total according to Situational Survey report 50 noncompliance standards were identified. Star champions are assigned work to make these 50 noncompliance standards in to complianced.

\section{*Star Champions}

All HODs made as Star Champions of their department, they assigned to implement the respective standards in their department.

\section{*Co- Champions}

All senior staff made as Co-Champions, assigned work to help chapter Champions and Co-Champions implementing the quality standards.

\section{*Committees}

Following various Committees are formed and role of each Committee explained.

1. Core assessment Committee - consist of NABH Co-ordinator, District surgeon, RMO and

2. Heads of various committees.

3. Internal assessment Committee - consist of Heads of various committees.

4. Safety Committee- consist of one of senior doctor as Safety Officer, Matron and Administrative officer and superintendent.

5. Hospital Infection Committee (HIC) - consist of Microbiologist and team members.

6. Quality Improvement Committee (QIC) consist of one of senior doctor as Quality officer and team members.

7. Pharmacotherapetic Committee - consist of Chief pharmacist and Pharmacists team.

8. Audit Committee- one of senior doctor as Audit officer and team members.

\section{B. Sensitisation}

To all staff of hospital, Sensitisation about Quality Standards is necessary. Sensitisation of staff can be done by conducting trainings as according to the training plans as shown in Fig.8. The Chapter champions should struggle to the Sensitize all staff regarding their allotted chapter standards. Training schedule should be planned. According the schedule trainings should be conducted, all training activities should be documented properly.

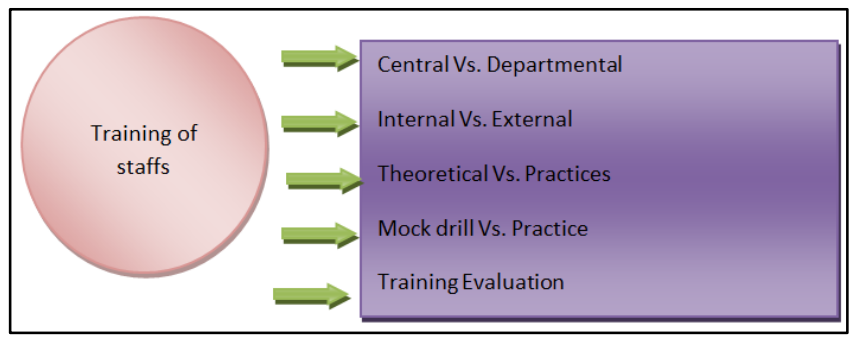

Fig. 8: Training Plans

\section{Understanding quality standards}

All Star champions and star champions with assistance of co-champions should help and guide the staff in understanding the qualitystandards.

\section{Documentation \\ Policies}

Each standard has to develop policies, which should describe the type of services going to catered with available resources, e.g. admission discharge policies. All HODs prepared respective departmental policies as per NABH/NABL guidelines.

\section{Procedures}

All departments should have standard operating procedures (SOPs). All departmental HODs prepared respective departmental SOPs as per NABH/NABL guidelines.

\section{Manuals}

All departments should have manuals, department heads should prepare their respective department manual. QIC should prepare hospital quality manual. So all manuals are prepared as per NABH/NABL guidelines.

\section{Guidelines}

Each department have Criteria and Protocols for each procedure in their department as per NABH/NABL guidelines. So all department HODs should stick to respective Criteria and Protocols as per NABH/NABL guidelines.

Each department should prepare Forms, Formats, Checklists and Standard Operating Procedures (SOPs) 
as per guidelines. All department HODs prepared them.

\section{Structural Standards Implementations Plans}

Each department heads prepare necessary infra structural plans, which includes requirements list about Human Resources, Equipments and Materials and submit that list to authority. So all department HODs prepared list and submitted. Authority should take action.

\section{Statutory Mandatory's Licences and Certificates \\ General}

1. Biomedical waste(BMW) management and handling Authorisation

2. Registration with Establishment Act

3. Registration with Local Authorities

4. Facility management:

5. Fire NO objection certificate (NOC).

6. Licences for Diesel storage

7. License to store compressed Gas

8. Registration for Boiler

9. Sanction/License for Lifts

\section{Radiology}

Registration for Modality

\section{Process of implementation of qualitystandards}

Aim of this process to ensure that NABH/NABL quality standards are implemented and integrated with hospital functions.

All Chapter champions should study the noncompliance quality standards as observed in Situational Survey report, took necessary actions, formation of committees training to staff, prepared necessary documents, resensitize staff about the plan to bridge gaps. Authority provided structural equipment and statutory requirements.

In implementation of Quality Standards, it also involves important programme is implementation of Quality Indicators. These Quality Indicators are documented statistical measures of quality of services. QIC conducted training to staff properly about the all NABH Quality Indicators, how to fill Quality Indicators forms, calculation, submission, periodic distribution, collection back process, and this all process should be supervised by QIC.

The most important Quality Indicators is "Patient Satisfaction Feedback Form", which highlights the quality of hospital services, helps in improvement. So QIC conducted trainings to staff from 20/02/2016 to
24/02/2016 and from 25/02/2016 distributed Quality Indicators forms to all functional areas of hospital. Implementation of noncompliance Quality Standards and Quality Indicators programme started from $25 / 02 / 2016$ to $25 / 03 / 2016$ under guidance of Internal assessment committee.

Similarly, hospital HIC should conduct training about HIC practices like BMW techniques and hand washing techniques implementation and about BMW check lists, hand washing check lists. HIC should conduct demonstration of BMW programme, hand washing techniques then HIC people should ask staff to demonstrate, HIC will supervise the staff demonstration, and write the check list. Periodically this programme should be conducted by HIC.

\section{Monitoring}

Implementation process strictly monitored by Internal assessment committee. From25/02/2016 to 25/03/2016 and they guide staff properly during this period for correct and successful implementation of noncompliance quality standards. Quality indicators programme monitored by QIC and HIC practices are monitored by HIC.

\section{Data analysis and observation}

All implemented Quality Indicators forms, formats and data are collected from 26/03/2016 to 27/03/16 by QIC and HICs and complied and analysed the data, then on 28/03/2016 submitted their supervised report as Quality Indicators Data Analysis Report to Core assessment committee. At the same time from $26 / 03 / 2016$ to 28/03/2016 Internal assessment committee did Intra Departmental and Inter Departmental wise assessment as in Fig.6, submitted its Internal assessment report to Core assessment committee on 29/03/2016. Finally Core assessment committee analysed the Quality Indicators Data Analysis Report and Internal assessment Report on $30 / 03 / 16$, observed for the implemented standards and their compliancy and noncompliance and prepared Final Report on 31/03/16. So Core assessment committee continuously, it will do its work, putting continuous efforts as shown in Fig. 9. 


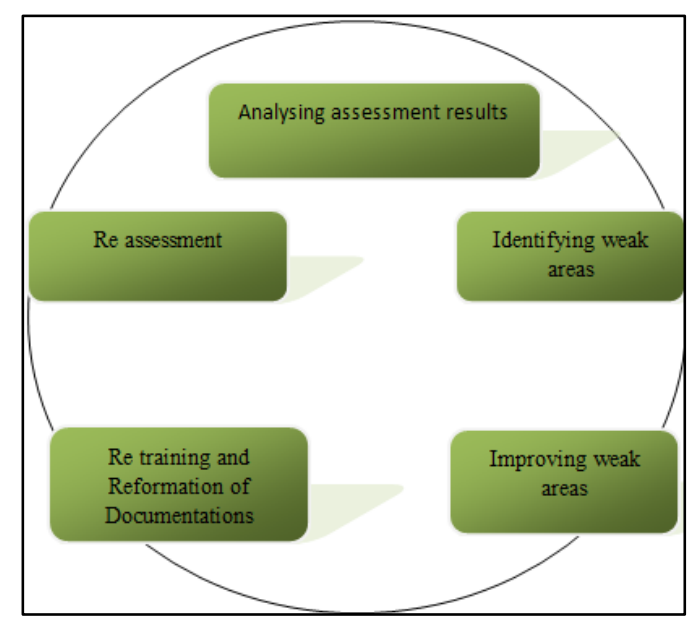

Fig. 9: Continuous Efforts by Core Assesment Team

\section{Final Report of quality standards by Core}

Assessment Committee as Follows - Core assessment committee reviewed and analysed Quality Indicators Data Analysis Report and Internal assessment report on 30/03/16 and observed the successful implemented quality indicators and formed final report on 31/03/16.

Among aim of implementation of total 50 noncompliance quality standards in the facility during the project period, it has observed at the end of project there are totally 37 quality standards are successfully implemented under the guidance of NABH coordinator and with the help of all committees efforts and staff orientation, dedication, and with support of organisation authority. Core assessment committee confirmed that implemented 37 quality indicators are implemented and are successfully adopted by staff across the facility and also they are actively performing this programme.

Randomly in wards and OPDs, patients and their attenders, submitted their 'Patient Satisfaction Feedback Reports"' to QIC. This QIC submitted these "Patient Satisfaction Feedback Reports" along with Quality Indicators Data Analysis Report to Core assessment committee. All these "Patient Satisfaction Feedback Reports', also studied and analysed by Core assessment committee and noted that patients and attenders are given valuable suggestions regarding the improvement of quality of the services across the facility.

Core assessment committee also noted HIC practices check lists i.e. BMW check lists and hand washing check lists, within project period most of the check lists reports shows staffs are made competitive in HIC practices.

\section{Discussion}

Hospital is an integral part of health care system. Accreditation would be the single most important approach for improving the quality of hospital ${ }^{2}$. So our hospital also decided for Accreditation to improve quality of health services. Often measuring the quality in health facilities has never been easy, more so in public health facilities ${ }^{5}$. So there must be quality linked measurement system, which primary role is to provide effective means to assuring the patients requirements are met fully ${ }^{4}$. NABH is member of ISQua accreditation Council. NABH is founder member of proposed Asian Society for Quality in Health Care (ASQua) being registered in Malaysia. The establishment of quality system in health care organisation facilitates the standardisation of the system and processes in both clinically and at administrative levels ${ }^{4}$. The main pillars of quality measurement system are quality standards 5 . The quality system thus act as vehicle for the quality care at hospitals ${ }^{4}$.The NABH quality standards are totally 102 and 636 objective elements. Objective elements are measurable components and these are required to be met in order to meet the requirement of a particular standard ${ }^{1}$.In our hospital during project period taken lot of care to meet the requirement of each standards.

All NABH 10 chapters are deciding factors to say whether hospital is meeting the requirements of the accreditation standard. These standards are dynamic process and would be under constant review process ${ }^{1}$, which was done carefully during our project study period. NABH's pre accreditation entry level standards will soon be followed by pre accreditation progressive level standards as in intermediate stage to full accreditation $^{6}$. Similarly in our project study among out of 50 noncompliance standards, 37 standards successfully made compliance and entered from pre accreditation entry level to full accreditation level and remaining 13 noncompliance standards, entered from pre accreditation entry level to progressive level, for which plan of action to be taken further to make them fully compliance. So our hospital successfully implemented and adapted majority NABH Quality Standards, hence itself prepared for Accreditation process. Recommendation plans can be done for those noncompliance quality standards to convert them as compliance quality standards, hence we can go for accreditation easily in future.

\section{Conclusion}

This study concluded that by studying the requirements of quality standards of NABH/NABL we can easily implement the quality standards of 
$\mathrm{NABH} / \mathrm{NABL}$, by which there is scope for improvement in quality of health services, improve in skills and responsibility of staff and can meet the patient's expectations.

\section{Source of funding}

None.

\section{Conflict of interest}

None.

\section{References}

1. Guide book to National Accreditation Board for the Hospital and Health care providers (NABH)-3rdEdition, Nov.2011.
2. NABH General Information Brochure, July.2012.

3. Guide book to National Accreditation Board for the Hospital and Health care providers (NABH)-4thEdition, Dec.2015.

4. Indian. J Community Med 2012: 37(3): 150-2.

5. Assessors guide book for quality assurance in District hospitals - vol.1, 2003.

6. Guide book for Pre accreditation Entry level standards for small health care organisations (SHCOs) -1St Edition, May.2015.

How to cite: Hiremani SG, Hosamani DS, Patil RM, More MB, Gundalli SM, Patil RG. To study the requirements of quality standards of NABH/ NABL. IP Int J Med Paediatr Oncol 2020;6(1):14-22. 